\title{
APRESENTAÇÃO DO DOSSIÊ MOVIMENTOS SOCIAIS E RESISTÊNCIA: A CONTRIBUIÇÃO DA PERSPECTIVA DISCURSIVA NA COMPREENSÃO DO BRASIL CONTEMPORÂNEO
}

\section{DOSSIER PRESENTATION SOCIAL MOVEMENTS AND RESISTANCE: THE CONTRIBUTION OF THE DISCURSIVE PERSPECTIVE IN THE UNDERSTANDING OF CONTEMPORARY BRAZIL}

Thalita Cristina Souza Cruz ${ }^{1}$ Fernanda Moraes D'Olivo ${ }^{2}$

Pensar e discutir os movimentos sociais considerando seus discursos, a produção de sentidos e seus efeitos na sociedade é de extrema relevância para a nossa atual conjuntura, em que observamos diversos esforços encabeçados por políticos do executivo, legislativo, bem como por parte da elite, em silenciar as lutas e, consequentemente, os movimentos sociais. Justamente por essa urgência na discussão do funcionamento desses movimentos que propusemos, para esta seção temática, refletir sobre os processos de resistência dos mais diversos grupos, tendo como enfoque os Estudos do Discurso. Mas, o que podemos compreender sobre tais movimentos a partir de suas discursividades, dos seus efeitos produzidos por meio de seus discursos de resistência?

Os Estudos do Discurso, propriamente dito, se desdobram em diferentes metodologias de análise e concepções de discurso, de ideologia e de sujeito, frequentemente utilizadas pelas Ciências Humanas e Sociais com o foco em compreender a manifestação e reprodução destes

\footnotetext{
1 Doutora e Mestra em Linguística pela Universidade Estadual de Campinas- Unicamp. e-mail: thalita.souza.cruz@gmail.com

2 Doutora Mestra em Linguística pela Universidade Estadual de Campinas- Unicamp. e-mail: fernanda.dolivo@gmail.com
} 
em processos sociais, buscando, sobretudo, entender as formas discursivas de resistência realizadas pelos diversos grupos sociais contra processos de dominação e de exploração.

Assim, nessa proposta levantamos algumas questões que, para nós, constituem-se como fundamentais para compreendermos o discurso de resistência na organização dos movimentos sociais, bem como os processos que estão em jogo na sua constituição. Também questionamos sobre as vozes que constroem e sustentam tais movimentos, com o objetivo de entender quais são postas em evidências e quais são apagadas.

Esses questionamentos se configuram como o mote desta seção temática e estão presentes no percurso dos artigos aqui publicados que, de forma precisa, apresentam-nos diferentes formas de movimentos sociais, diferentes formas de Insubmissão necessárias para a luta em prol dos direitos das minorias.

Iniciamos a seção com o artigo Nunca foram acidentes, sempre são desastres e crimes: narrativas, disputas e resistências na zona de sacrifício de Barcarena, de Eunápio Dutra Carmo (UEPA) que, a partir das análises do Movimento Barcarena Livre nos faz refletir sobre "as formas de resistência para garantir os direitos territoriais dos moradores, comunidades tradicionais e ribeirinhas", problematizando um discurso hegemônico acerca dos conflitos socioambientais. Vemos, aqui, as lutas travadas por esse movimento na construção de uma narrativa outra acerca dos acidentes e crimes ambientais, convenientemente nomeados pelas grandes mineradoras de "desastres naturais". Ao tentar descontruir essa narrativa, outro discurso se mostra sustentando a narrativa desse movimento social.

Também buscando pensar sobre os processos de funcionamento da resistência que sustentam os movimentos sociais, temos o artigo Comunidades negras quilombolas: a agonia de um movimento social abandonado pelo Estado, de Adelmir Fiabani (UFFS), que nos traz um percurso histórico sobre as políticas voltadas para a titulação de terras quilombolas que, muitas vezes, age no sentido de atrasar o processo e não de garanti-lo. A resistência, nesse artigo, é observada pela luta constante dessas comunidades para garantir os seus direitos, logo, a sua existência. 
Em seguida, o artigo $O$ setor da saúde: um coletivo mobilizado em defesa da vida das famílias no acampamento sem-terra da Anoni, de Alessandra Regina Müller Germani (UFFS), Jacir João Chies (UFPEL) e Clayton Hillig (UFSM), traz para a discussão a luta por um trabalho de saúde voltado para as condições específicas dos acampamentos sem-terra, em especial, o acampamento Anoni, no Rio Grande do Sul. Nesse artigo, busca-se identificar, a partir de diferentes vozes dos agentes de prática popular de saúde, a construção de uma prática que estabeleça a relação entre os saberes científicos e populares. Entender como se dá esse movimento acerca de uma luta pelo direito à saúde dentro de uma outra luta - pelo direito à terra - se dá por meio da análise dos dizeres materializados nas vozes desses agentes.

O próximo artigo que compõe a revista é $O$ desejo de (des)habitar o outro: o corpo Quare na prática de Waldo Motta, de Fernando Luis de Morais e Claudia Maria Ceneviva Nigro (ambos da UNESP), cujo foco é sobre os corpos negros, gays e pobres, que se materializam nas e pelas tramas poéticas de Waldo Motta. A partir da compreensão da(s) voz(es) poética desse autor, podemos ver as estratégias discursivas na construção dos sentidos acerca do corpo Quare.

Fechando este volume, temos o artigo Refundação do Estado e diálogo intercultural: o coletivo Yasunidxs da defesa da democracia, Fabian Cevallos Vivar (CESCoimbra), Fabian Cevallos Vivar (CES-Coimbra)que busca analisar os movimentos de resistência, trazendo à tona as diferentes formas de contato de lutas indígenas, ambientais e feministas que buscam alternativas de viver sem a dependência do petróleo. Nesse artigo, conhecemos o Coletivo Yasunidxs a favor da defesa do Parque Nacional Yasuní e da Democracia do Equador, que nos mostra como se dá o interessante processo de resistência polifônico na luta pelo meio ambiente, em oposição à exploração exacerbada do parque.

Como se observa nos artigos selecionados para este volume, não se trata, portanto, de um método de análise apenas do texto - seja ele falado ou escrito - mas de uma área interdisciplinar do conhecimento que se vale de diferentes métodos qualitativos - estudos etnográficos, estudo de caso, análise de mecanismos linguístico-discursivos, análise gramatical, dentre outros -, que nos permitem compreender os processos de constituição de 
sentidos, de produção de narrativas outras que os fortalecem cada vez mais, mesmo em um momento em que nossos direitos estão prestes a serem destruídos.

Convidamos a todos os leitores e leitoras da revista para a leitura dos trabalhos apresentados. Porém, não podemos terminar essa introdução, em contexto tão particular quanto o vivido neste momento no Brasil e no mundo devido à pandemia de Coronavírus, sem convidá-los a refletir sobre os perigos e possibilidades dos discursos atuais, em que a disputa de narrativas podem trazer consequências desastrosas para a humanidade em geral. 